Check for updates

Cite this: RSC Adv., 2018, 8, 14152

Received 24th February 2018

Accepted 11th April 2018

DOI: $10.1039 / \mathrm{c} 8 \mathrm{ra01636d}$

rsc.li/rsc-advances

\section{Advantage of semi-ionic bonding in fluorine-doped carbon materials for the oxygen evolution reaction in alkaline media $\dagger$}

\begin{abstract}
Jeheon Kim, ${ }^{a}$ Ruifeng Zhou, (DD ${ }^{\text {ab }}$ Kei Murakoshi (D) *a and Satoshi Yasuda (D) a
Metal-free carbonaceous catalysts have potential applications for oxygen evolution reaction (OER) devices because of their low-cost and abundant supply. We report that fluorine-doped carbon black is an active catalyst for OER. Fluorine-doped carbon black (F-KB) is simply synthesized by the pyrolysis of KETJENBLACK (KB) as carbon substrate with Nafion as fluorine precursor. As a result, the OER activity of $\mathrm{F}-\mathrm{KB}$ is significantly higher than that of pristine KB in alkaline media. The OER catalytic activity of F-KB is found to be dependent on the quantity and characteristics of carbon-fluorine bonding $(\mathrm{C}-\mathrm{F})$ which can be controlled by the pyrolysis temperature. It is further found that the OER activity depends on the quantity of semi-ionic $\mathrm{C}-\mathrm{F}$ bonds, but not covalent $\mathrm{C}-\mathrm{F}$ bonds. This result proves the importance of carbon atoms with semi-ionic $\mathrm{C}-\mathrm{F}$ bonds as the active sites for OER.
\end{abstract}

\section{Introduction}

Electrochemical energy conversion and storage systems have attractive potential for clean energy applications. As an energy conversion system, electrochemical water splitting has been used to produce hydrogen. ${ }^{1}$ In such a system, the hydrogen evolution reaction (HER) proceeds simultaneously with the oxygen evolution reaction (OER) at the cathode and anode, respectively. ${ }^{2}$ It is known that the efficiency of electrochemical water splitting is limited by the activity of the OER because it is a 4-electron reaction in comparison with the 2-electron reaction of HER, which results in a much higher overpotential. ${ }^{3}$ Conventionally, precious metal oxides, such as ruthenium oxide $\left(\mathrm{RuO}_{2}\right)$ and iridium oxide $\left(\mathrm{IrO}_{2}\right)$, are widely used as catalysts for OER owing to their inherent catalytic properties. ${ }^{4,5}$ However, the precious metal oxides are expensive and are in limited commercial supply.

Metal-free heteroatom-doped carbon has come into focus as catalysts for OER owing to its abundance, low cost and high electric conductivity. For example, Hashimoto et al. reported that nitrogen-doped carbon exhibits catalytic activity for OER. ${ }^{6}$ Furthermore, the OER activity of nitrogen-doped carbon can be enhanced by increasing the levels of pyridinic and quaternary nitrogen. In these nitrogen-doped carbons, positively charged carbon atoms act as active sites of OER because $\mathrm{OH}^{-}$in the

\footnotetext{
${ }^{a}$ Department of Chemistry, Faculty of Science, Hokkaido University, Sapporo, 060-0810, Japan.E-mail: kei@sci.hokudai.ac.jp

${ }^{b}$ Institute for International Collaboration, Hokkaido Univ., Sapporo, 060-0815, Japan $\dagger$ Electronic supplementary information (ESI) available. See DOI: 10.1039/c8ra01636d
}

electrolyte have lower adsorption energy on the positively charged active sites. ${ }^{6}$

Among the heteroatom-doped carbons, fluorine-doped carbon has been studied as an OER catalysts using density functional theory (DFT). ${ }^{7,8}$ Fluorine atoms have the highest electronegativity among all the elements, therefore they induce the highest positive charge on carbon atoms when they are bonded, which has great potential for the OER. ${ }^{9}$ In normal DFT study, the carbon atom bonded to fluorine was in $\mathrm{sp}^{3}$ hybridization, which resulted in a covalent C-F bond. ${ }^{7,8}$ However, the $\mathrm{C}-\mathrm{F}$ bond can also be ionic or semi-ionic. An ionic C-F bond appears on a carbon atom of $\mathrm{sp}^{2}$ hybridization from graphitic structure, whereas a semi-ionic C-F bond is an intermediate state between covalent and ionic bond. ${ }^{10,11}$ In general, semiionic bonds have higher polarities than covalent $\mathrm{C}-\mathrm{F}$ bonds, which result in higher positive charge on carbon atoms. ${ }^{12}$ Therefore, the fluorine-doped carbon with semi-ionic C-F bonds should have a greater activity for OER than that with the covalent $\mathrm{C}-\mathrm{F}$ bonds.

Various fluorine precursors have been used to synthesize fluorine-doped carbon. ${ }^{11,13-15}$ In a previous work, fluorine-doped graphite was synthesized by a long-time reactor process using fluorine gas, which resulted in the formation of ionic and covalent C-F bonds. ${ }^{13,16}$ In another method, solution plasma synthesis was performed using trifluorotoluene as the fluorine precursor. ${ }^{14}$ As a result, the synthesized fluorine-doped carbon had a high semi-ionic C-F ratio. The OER activity of fluorinedoped carbon has not been studied to date. The relationship between the OER activity and the characteristics of C-F bonds is unclear.

In this study, we evaluated the OER activity of fluorine-doped carbon. Nafion was used as the fluorine precursor. In situ $\mathrm{O}_{2}$ 
monitoring voltammetry was used for the evaluation of the OER activity of the catalysis. The ionicity of C-F bond in the catalysis was determined by X-ray photoelectron spectroscopy (XPS) to evaluate the correlation between the C-F bonding and the activity.

\section{Experimental}

\section{Sample preparation}

Nafion (5\% dispersion solution), $\mathrm{KB}$ (EC-600JD), and $\mathrm{RuO}_{2}$ (99.9\%) were purchased from Wako Pure Chemical Industries, LTD., Lion Special Chemicals Co., LTD., and Sigma-Aldrich, respectively. In a typical synthesis of F-KB with a mass ratio between Nafion and KB of $40: 1$ (40F-KB), Nafion $(400 \mu \mathrm{L})$ and $\mathrm{KB}(10 \mathrm{mg})$ were dispersed using an ultrasonication homogenizer (SMT UH-50F) at $50 \mathrm{~W}$ and $20 \mathrm{kHz}$ in methanol $(10 \mathrm{~mL}$ ) for $30 \mathrm{~min}$. After drying overnight at $60{ }^{\circ} \mathrm{C}$, the mixture was pyrolyzed in $\mathrm{Ar}(200 \mathrm{sccm})$ for 1 hour at various temperatures. KB was also heated at $600{ }^{\circ} \mathrm{C}$ for 1 hour before OER test.

\section{Catalyst characterization}

The sample $(1 \mathrm{mg})$ was dispersed in ethanol $(40 \mu \mathrm{L})$ and deionized water $(160 \mu \mathrm{L})$ using an ultrasonic homogenizer for $10 \mathrm{~min}$. Nafion $(2 \mu \mathrm{L})$ was then added to the composite ink and dispersed by the ultrasonic homogenizer for $1 \mathrm{~min}$. The catalyst $(8.3 \mu \mathrm{L})$ was loaded onto a rotation disk electrode (RDE) as the working electrode. The RDE has a glassy carbon disk of diameter of $0.5 \mathrm{~cm}$ (catalyst loading: $0.2 \mathrm{mg} \mathrm{cm}^{-2}$ ). The electrochemical cell was equipped with a dissolved $\mathrm{O}_{2}$ detector (Pyroscience OXROB10), the working electrode, a Pt counter electrode, a reversible hydrogen electrode (RHE) as the reference electrode and $0.1 \mathrm{M} \mathrm{KOH}$ as electrolyte, as shown in Fig. S9. $\dagger$ The distance between the dissolved $\mathrm{O}_{2}$ detector and working electrode was $5 \mathrm{~mm}$. KB and 40F-KBs were pre-treated by chronoamperometry at a constant potential of $1.6 \mathrm{~V}$ for $1 \mathrm{~min}$ to avoid the current from carbon oxidation in OER. To minimize the dissolved $\mathrm{O}_{2}$ before measurements, the electrolyte was bubbled with Ar gas. Background $\mathrm{O}_{2}$ concentration was subtracted from all data of $\mathrm{O}_{2}$ concentration versus time. Linear sweep hydrodynamic voltammetry was performed from $1.0 \mathrm{~V}$ to $1.6 \mathrm{~V}$ with a scan rate of $10 \mathrm{mV} \mathrm{s}^{-1}$. Rotation speed of the RDE was maintained at $1600 \mathrm{rpm}$. Dissolved $\mathrm{O}_{2}$ concentration was recorded at $1.6 \mathrm{~V}$ for $10 \mathrm{~min}$. X-Ray photoelectron spectroscopy (XPS) was conducted using a JEOL JPS-9200 with a monochromatic $\mathrm{Al} \mathrm{K} \alpha \mathrm{X}$-ray source (1486.6 eV). O 1s at $531.0 \mathrm{eV}$ was used as internal standard peak for XPS measurements. Atomic ratios of $\mathrm{C}, \mathrm{F}$ and $\mathrm{O}$ were estimated from the areas of their $1 \mathrm{~s}$ peaks and relative sensitivity factors $(0.25: 1: 0.66)$. F 1 s of semi-ionic C-F and covalent C-F have peaks at $687.0 \mathrm{eV}$ and $689.0 \mathrm{eV}$ of full width at half maximum (FWHM) of $2.1 \mathrm{eV}$ and $6.2 \mathrm{eV}$, respectively as shown in Fig. 3(d). $\mathrm{N}_{2}$ adsorptiondesorption isotherms were obtained by using a Yuasa Ionics Autosorb 6AG at $77 \mathrm{~K}$. Specific surface areas were estimated by the Brunauer-Emmett-Teller (BET) method. Raman spectra were recorded from 300 to $3200 \mathrm{~cm}^{-1}$ with Nanofinder 30 (Tokyo Instrument, Inc.) using a $514 \mathrm{~nm}$ laser beam.

\section{Results and discussion}

Fig. 1a shows the linear sweep hydrodynamic voltammograms of $\mathrm{RuO}_{2}, \mathrm{~KB}$, and F-KB after electrochemical pretreatment (see in ESI $\dagger$ for details). The catalyst loading was $0.2 \mathrm{mg} \mathrm{cm}^{-2}$ for all samples. KB exhibited the lowest current density of $0.8 \mathrm{~mA}$ $\mathrm{cm}^{-2}$ at potential of $1.6 \mathrm{~V}$, whereas the current density of $40 \mathrm{~F}-\mathrm{KB}$ was $2.6 \mathrm{~mA} \mathrm{~cm} \mathrm{~cm}^{-2}$. These results showed that the electrochemical activity of the KB can be enhanced by fluorine doping. According to related studies, the OER current densities of phosphorus-doped graphene and nitrogen-phosphorus-doped graphene were $19 \mathrm{~mA} \mathrm{~cm}{ }^{-2}$ and $4 \mathrm{~mA} \mathrm{~cm} \mathrm{~cm}^{-2}$ at $1.6 \mathrm{~V}$ versus RHE, respectively (catalyst loading: $0.2 \mathrm{mg} \mathrm{cm}^{-2}$ ). ${ }^{17,18}$ Surfaceoxidized multi-walled carbon nanotubes had a current density of $0.8 \mathrm{~mA} \mathrm{~cm} \mathrm{~cm}^{2}$ at $1.6 \mathrm{~V}$ versus RHE (catalyst loading: $1 \mathrm{mg}$ $\left.\mathrm{cm}^{-2}\right) .{ }^{19}$ Our $40 \mathrm{~F}-\mathrm{KB}$ showed a relatively lower activity than nitrogen- or phosphorus-doped carbon, but a higher current density than the oxygen-doped carbon. In the case of $\mathrm{RuO}_{2}$, the current density was approximately $6.5 \mathrm{~mA} \mathrm{~cm}^{-2}$ at $1.6 \mathrm{~V}$.

Next, we evaluated the evolved $\mathrm{O}_{2}$ by in situ measurement with an $\mathrm{O}_{2}$ detector at a constant potential of $1.6 \mathrm{~V}$ for $10 \mathrm{~min}$. The results are shown in Fig. 1b. In the case of the pristine $\mathrm{KB}$, the $\mathrm{O}_{2}$ concentration change was not observed over the $10 \mathrm{~min}$. However, the $\mathrm{O}_{2}$ concentration from $40 \mathrm{~F}-\mathrm{KB}$ gradually increased
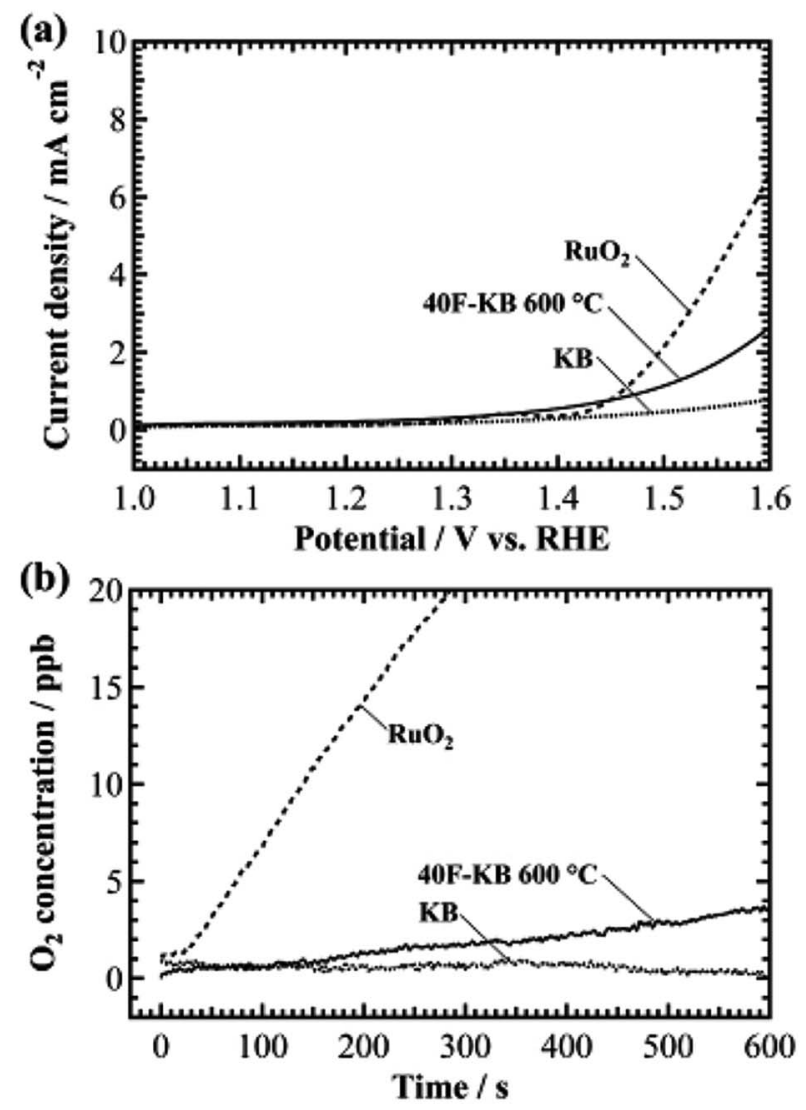

Fig. 1 (a) Linear sweep hydrodynamic voltammogram (scan rate $10 \mathrm{mV} \mathrm{s}^{-1}$ ) and (b) $\mathrm{O}_{2}$ concentration versus time for 40F-KB (solid lines), $\mathrm{RuO}_{2}$ (dashed line), and $\mathrm{KB}$ (dotted line) on RDE (1600 rpm) in $0.1 \mathrm{M} \mathrm{KOH}$. Chronoamperometry was measured at $1.6 \mathrm{~V}$. 
to approximately $3.7 \mathrm{ppb}$ after $10 \mathrm{~min}$. The increment of the $\mathrm{O}_{2}$ concentration for $\mathrm{RuO}_{2}$ was approximately 40 ppb over $10 \mathrm{~min}$. Hence, $40 \mathrm{~F}-\mathrm{KB}$ has a catalytic activity of approximately $10 \%$ that of $\mathrm{RuO}_{2}$. The results prove that the catalytic activity for OER can be enhanced by fluorine doping on an inactive carbon substrate.

To verify the OER activity of $\mathrm{F}-\mathrm{KB}$ with various synthetic conditions, different pyrolysis temperatures were employed. The pyrolysis temperatures were set at $400{ }^{\circ} \mathrm{C}, 500{ }^{\circ} \mathrm{C}, 600{ }^{\circ} \mathrm{C}$, $700{ }^{\circ} \mathrm{C}$, and $800{ }^{\circ} \mathrm{C}$. Linear sweep hydrodynamic voltammetry of different 40F-KBs were performed and the results are shown in Fig. 2a. 40F-KB $600{ }^{\circ} \mathrm{C}$ and $40 \mathrm{~F}-\mathrm{KB} 700{ }^{\circ} \mathrm{C}$ exhibited higher OER current densities than KB. Other 40F-KBs had lower OER current densities than $\mathrm{KB}$. We also confirmed similar tendency in the increment of the $\mathrm{O}_{2}$ concentration at a constant potential of $1.6 \mathrm{~V}$, as shown in Fig. $2 \mathrm{~b}$. The noise for the $\mathrm{O}_{2}$ concentration measurement was approximately $0.3 \mathrm{ppb}$. The $40 \mathrm{~F}-\mathrm{KB} 400{ }^{\circ} \mathrm{C}$ exhibited no higher $\mathrm{O}_{2}$ signal than the noise. The $\mathrm{O}_{2}$ concentrations of the $500{ }^{\circ} \mathrm{C}$ and $800{ }^{\circ} \mathrm{C}$ samples slightly increased over $10 \mathrm{~min}$. However, the $\mathrm{O}_{2}$ concentration of the $600{ }^{\circ} \mathrm{C}$ and $700{ }^{\circ} \mathrm{C}$ samples increased by over $1.7 \mathrm{ppb}$ over $10 \mathrm{~min}$. These results showed that catalytic activity for OER can be affected by the pyrolysis temperature.
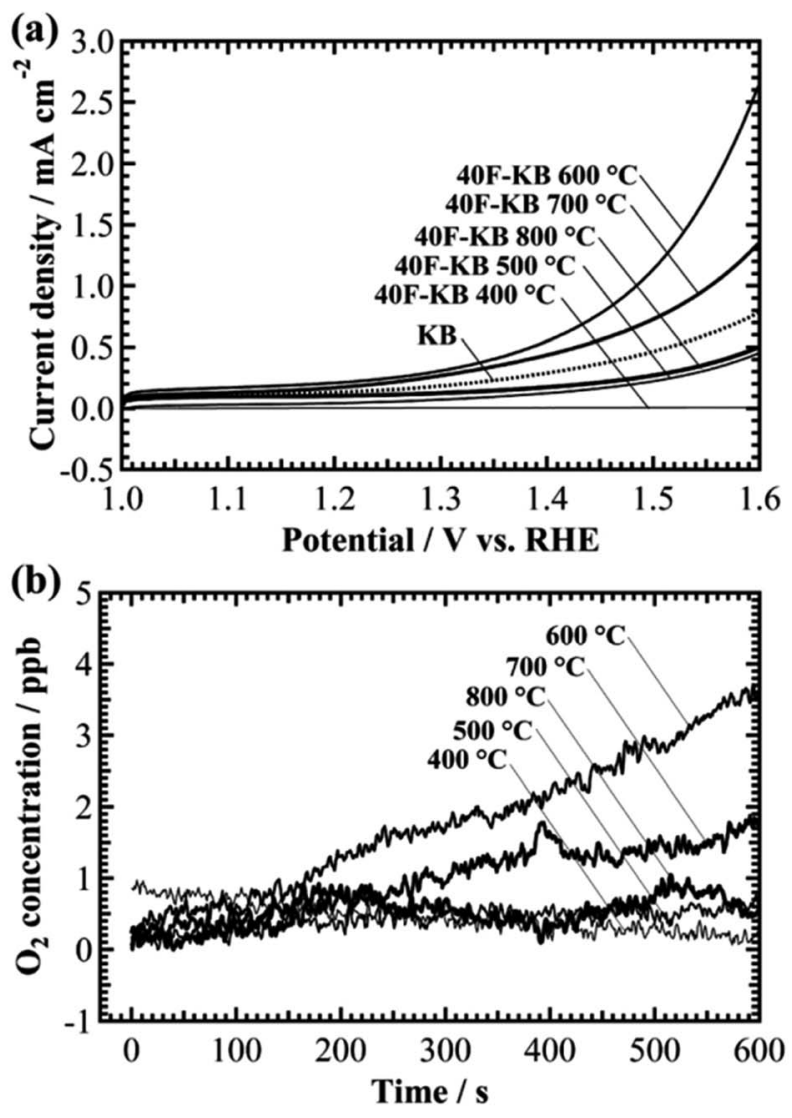

Fig. 2 (a) Linear sweep hydrodynamic voltammograms of 40F-KBs (solid lines) and KB (dotted line) on RDE (1600 rpm) in 0.1 M KOH. Scan rate $10 \mathrm{mV} \mathrm{s}^{-1}$. (b) $\mathrm{O}_{2}$ concentration versus time of $40 \mathrm{~F}-\mathrm{KBs}$ on RDE (1600 rpm). Solid line is bolder with increasing pyrolysis temperature from $400{ }^{\circ} \mathrm{C}$ to $800^{\circ} \mathrm{C}$. Chronoamperometry was measured at $1.6 \mathrm{~V}$.
The specific surface area (SSA) was measured to clarify the relationship between the OER activity and the SSA of the samples (Fig. S3†). The SSAs of samples are represented in Table $\mathrm{S} 1 . \dagger$ The SSA of $\mathrm{KB}, 40 \mathrm{~F}-\mathrm{KB} 800{ }^{\circ} \mathrm{C}, 40 \mathrm{~F}-\mathrm{KB} 600{ }^{\circ} \mathrm{C}$, and $40 \mathrm{~F}-\mathrm{KB}$ $400{ }^{\circ} \mathrm{C}$ were $2177 \mathrm{~m}^{2} \mathrm{~g}^{-1}, 1597 \mathrm{~m}^{2} \mathrm{~g}^{-1}, 1488 \mathrm{~m}^{2} \mathrm{~g}^{-1}$, and $687 \mathrm{~m}^{2}$ $\mathrm{g}^{-1}$, respectively. It indicates that Nafion remained on the $40 \mathrm{~F}-$ $\mathrm{KB} 400{ }^{\circ} \mathrm{C}$, which resulted in filled pores. The $\mathrm{N}_{2}$ adsorptiondesorption isotherm of $40 \mathrm{~F}-\mathrm{KB} 600{ }^{\circ} \mathrm{C}$ and $40 \mathrm{~F}-\mathrm{KB} 800{ }^{\circ} \mathrm{C}$ were almost the same, which indicates complete decomposition of Nafion. However, 40F-KB $800{ }^{\circ} \mathrm{C}$ exhibited a much lower OER activity than $40 \mathrm{~F}-\mathrm{KB} 600^{\circ} \mathrm{C}$. Therefore, the catalytic activity was not related to SSA in 40F-KBs. Raman spectroscopy was also used to investigate the details of the structure of $40 \mathrm{~F}-\mathrm{KBs}$ (Fig. S4 $\dagger$ ). KB and 40F-KBs exhibited the same Raman spectra. Thus, the disordered graphitic structure was maintained, even though fluorine was doped in KB. It should be emphasized that we performed chronoamperometry and in situ $\mathrm{O}_{2}$ concentration measurement for $40 \mathrm{~min}$ for the analysis of the durability as shown in Fig. S2. $\dagger$ As a result, current density gradually decreased to a few $\mu \mathrm{A} \mathrm{cm}{ }^{-2}$ over $30 \mathrm{~min}$ (Fig. S2a $\dagger$ ). Besides, $\mathrm{O}_{2}$ concentration also saturated at about 7 ppb after $30 \mathrm{~min}$. Thus, 40F-KB shows OER catalytic activity for 30 minutes.

To demonstrate the correlation between the OER activity and $\mathrm{C}-\mathrm{F}$ bonding, the 40F-KBs were investigated by XPS. The atomic ratios of carbon, fluorine and oxygen are shown in Table 1. No correlation between OER activity and oxygen ratio is found. The XPS near $\mathrm{C} 1 \mathrm{~s}$ and $\mathrm{F} 1 \mathrm{~s}$ regions are shown in Fig. 3. In the case of Nafion, $\mathrm{C}$ 1s and $\mathrm{F}$ 1s appeared at $292.0 \mathrm{eV}$ and $689.0 \mathrm{eV}$, respectively (Fig. 3(a) and (b)). The XPS of KB and F-KBs are shown in Fig. 3(c) and (d). In comparison with Nafion, pristine KB did not show F 1s peak (Fig. 3(b)), whereas the F 1s peak was observed from 40F-KBs (Fig. 3(d)). Furthermore, 40F-KB $600{ }^{\circ} \mathrm{C}$ did not show $\mathrm{S} 2 \mathrm{p}$ peak, which suggested the sulfate group $\left(-\mathrm{SO}_{3} \mathrm{H}\right)$ was completely removed by the pyrolysis at $600{ }^{\circ} \mathrm{C}$ (Fig. S5 $\dagger$ ). For the $40 \mathrm{~F}-\mathrm{KB} 400{ }^{\circ} \mathrm{C}$, peaks at $292.0 \mathrm{eV}$ and $284.5 \mathrm{eV}$ were present. The peak at $284.5 \mathrm{eV}$ is well-known to be attributed to the pure carbon. This result suggests that $40 \mathrm{~F}-\mathrm{KB} 400{ }^{\circ} \mathrm{C}$ is mixture of Nafion and the $\mathrm{KB}$, and $400{ }^{\circ} \mathrm{C}$ is too low for the decomposition of Nafion. With increased temperature, the fluorine peak was shifted towards the lower binding energy by approximately $2.0 \mathrm{eV}$, and the intensity of the carbon peak at $292.0 \mathrm{eV}$ was decreased. Furthermore, the quantity of fluorine also decreased with the increase of the pyrolysis temperature, as shown in Table 1. In particular, the fluorine peak of $40 \mathrm{~F}-\mathrm{KB}$ $600{ }^{\circ} \mathrm{C}$ can be deconvoluted into $689.0 \mathrm{eV}$ and $687.0 \mathrm{eV}$, which are $\mathrm{F}$ atoms with covalent and semi-ionic $\mathrm{C}-\mathrm{F}$ bonds,

Table 1 Atomic ratios of 40F-KBs (c: covalent and s: semi-ionic)

\begin{tabular}{llll}
$\begin{array}{l}\text { Pyrolysis } \\
\text { temperature }\end{array}$ & $\mathrm{C}[\%]$ & $\mathrm{F}[\%]$ & $\mathrm{O}[\%]$ \\
\hline $400{ }^{\circ} \mathrm{C}$ & 65.6 & 32.3 (c: $32.3, \mathrm{s:}$ 0) & 2.1 \\
$500{ }^{\circ} \mathrm{C}$ & 90.0 & 6.2 (c: 3.3, s: 2.9$)$ & 3.8 \\
$600{ }^{\circ} \mathrm{C}$ & 90.8 & 5.5 (c: 1.6, s: 3.9$)$ & 3.7 \\
$700{ }^{\circ} \mathrm{C}$ & 92.4 & 4.9 (c: 1.4, s: 3.5$)$ & 2.9 \\
$800{ }^{\circ} \mathrm{C}$ & 95.0 & 2.9 (c: 0.8, s: 2.1$)$ & 5.9
\end{tabular}



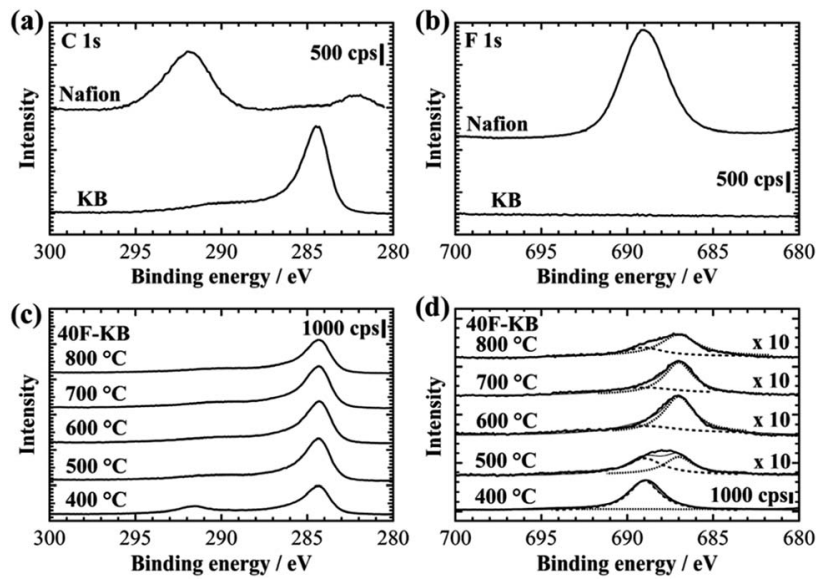

Fig. 3 XPS spectra for the $C$ 1s ( $a$ and $c$ ) and $F$ 1s ( $b$ and $d$ ) ranges for Nafion (top of $a$ and b), KB (bottom of $a$ and b), and 40F-KBs (c and d). Ascending order of XPS spectra of $40 \mathrm{~F}-\mathrm{KBs}$ (c and $\mathrm{d}$ ) is plotted on increasing pyrolysis temperature of $400{ }^{\circ} \mathrm{C}, 500^{\circ} \mathrm{C}, 600^{\circ} \mathrm{C}, 700^{\circ} \mathrm{C}$, and $800{ }^{\circ} \mathrm{C}$.

respectively. ${ }^{20}$ In addition, semi-ionic $\mathrm{C}-\mathrm{F}$ bond increases with pyrolysis temperature up to $600{ }^{\circ} \mathrm{C}$, and start to decrease above $600{ }^{\circ} \mathrm{C}$. The maximum semi ionic to covalent bond ratio $(\sim 5: 2)$ is reached at $600{ }^{\circ} \mathrm{C}$. On the other hand, carbon fluoride also decomposes at high temperature, reducing the total amount of F. Thus $600{ }^{\circ} \mathrm{C}$ is the optimized temperature considering both semi ionic ratio and total $\mathrm{F}$ content. This result means that the $\mathrm{C}-\mathrm{F}$ bonding can easily be controlled by the pyrolysis temperature. The changes from covalent $\mathrm{C}-\mathrm{F}$ to semi-ionic $\mathrm{C}-\mathrm{F}$ by raising the pyrolysis temperature of Nafion have not been reported previously.

As shown in Table 1, the maximum ratio of semi-ionic $\mathrm{C}-\mathrm{F}$ bonding was achieved on the $40 \mathrm{~F}-\mathrm{KB} 600{ }^{\circ} \mathrm{C}$. We plotted the $\mathrm{O}_{2}$ production as a function of the atomic ratio of semi-ionic $\mathrm{C}-\mathrm{F}$ bonding, as shown in Fig. 4. The $\mathrm{O}_{2}$ concentration was recorded at $1.6 \mathrm{~V}$ after $10 \mathrm{~min}$. As a result, the $\mathrm{O}_{2}$ concentration increased with the increase of the atomic ratio of semi-ionic $\mathrm{C}-\mathrm{F}$. These results strongly indicate that OER occurs on the carbon atoms

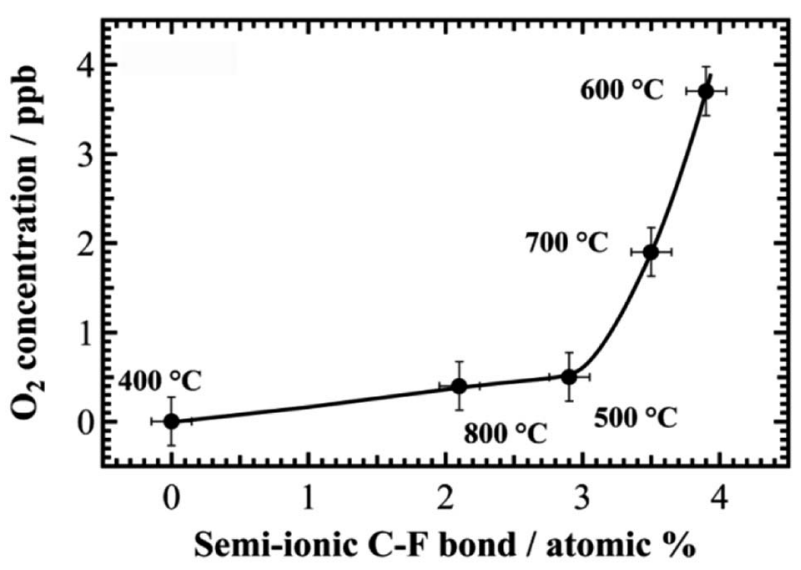

Fig. $4 \mathrm{O}_{2}$ concentration versus atomic ratio (\%) of semi-ionic $\mathrm{C}-\mathrm{F}$ bonds for $40 \mathrm{~F}-\mathrm{KBs}$. $\mathrm{O}_{2}$ concentrations were recorded at $1.6 \mathrm{~V}$ constant potential after $10 \mathrm{~min}$. with semi-ionic $\mathrm{C}-\mathrm{F}$ bonds. In particular, the OER activity is dramatically increased when the atomic ratio of semi-ionic $\mathrm{C}-\mathrm{F}$ bond is above $3 \%$. A probable reason is that neighboring carbon atoms both with semi-ionic $\mathrm{C}-\mathrm{F}$ bonding have synergistic effect to further enhance OER activity.

The Nafion usage dependence results support our suggestion (Fig. S6 and S7 $\dagger$ ). The $20 \mathrm{~F}-\mathrm{KB} 600{ }^{\circ} \mathrm{C}$ had a Nafion to $\mathrm{KB}$ mass ratio of 20 to 1 and a pyrolysis temperature of $600{ }^{\circ} \mathrm{C}$. The OER activity of $20 \mathrm{~F}-\mathrm{KB} 600{ }^{\circ} \mathrm{C}$ was similar to $40 \mathrm{~F}-\mathrm{KB} 500{ }^{\circ} \mathrm{C}$. Meanwhile, 20F-KB $600{ }^{\circ} \mathrm{C}$ and $40 \mathrm{~F}-\mathrm{KB} 500{ }^{\circ} \mathrm{C}$ possessed an equal quantity of semi-ionic $\mathrm{C}-\mathrm{F}$ bonding but different amounts of covalent $\mathrm{C}-\mathrm{F}$ bonding (Table 1 and $\mathrm{S} 2 \dagger$ ). Based on this result, we proved that the covalent $\mathrm{C}-\mathrm{F}$ bond is inactive for OER. Dresselhaus et al. reported that covalent $\mathrm{C}-\mathrm{F}$ bonds appear on carbon with $\mathrm{sp}^{3}$ hybridization. ${ }^{\mathbf{1 0}}$ Ito and co-workers suggested that covalent $\mathrm{C}-\mathrm{F}$ bonds are formed on buckled carbon sheet, while semi-ionic bonds are formed on planar carbon sheet. ${ }^{20}$ Therefore, if a fluorine atom is bonded to a defect of the graphitic structure, a covalent $\mathrm{C}-\mathrm{F}$ bond is formed. However, a semi-ionic C-F bond can be formed from the $2 \mathrm{p}_{z}$ orbital of a carbon atom which is perpendicular to the graphene plane. In general, the semi-ionic $\mathrm{C}-\mathrm{F}$ bonds have higher polarity than the covalent $\mathrm{C}-\mathrm{F}$ bonds. ${ }^{12}$ Therefore, adsorption of $\mathrm{OH}^{-}$in the first step of OER can be accelerated at the higher positively charged carbon with semi-ionic $\mathrm{C}-\mathrm{F}$ bonds, leading to higher OER activity.

\section{Conclusions}

Fluorine-doped carbon was successfully synthesized by pyrolysis of KB with Nafion. Electrochemical characterization and detection of the $\mathrm{O}_{2}$ production were performed on the resulting fluorine-doped carbon. The OER activity was found to be enhanced by fluorine doping. Furthermore, the nature and quantity of $\mathrm{C}-\mathrm{F}$ bonds can be controlled by the pyrolysis temperature. It is found that the increase of OER activity depends on the quantity of semi-ionic $\mathrm{C}-\mathrm{F}$ bonds. The fluorine doped carbon pyrolyzed at $600{ }^{\circ} \mathrm{C}$ had the most semi-ionic $\mathrm{C}-\mathrm{F}$ bonding (3.9\%), which showed the best OER performance. These results suggest that OER occurs on carbon atoms with semi-ionic $\mathrm{C}-\mathrm{F}$ bonding because of their very high positive charge. In addition, we discovered that non-linear relation between OER activity and the atomic ratio of semi-ionic C-F. This result implies that there may be synergistic effect between neighboring semi-ionic $\mathrm{C}-\mathrm{F}$ bondings. Our results exemplify the effect of charge on carbon atoms for the OER, and the design of metal-free heteroatom-doped carbon.

\section{Conflicts of interest}

There are no conflicts to declare.

\section{Acknowledgements}

The authors thank Dr Tomohiro Fukushima and Dr Hiro Minamimoto for valuable discussion and comments on the OER mechanism. This study was supported by the Japan Science and 
Technology Agency, PRESTO and JSPS KAKENHI Grant Numbers 15K05465, 26248001, and $16 \mathrm{H} 06506$ (Scientific Research on Innovative Areas "Nano-Material OpticalManipulation").

\section{Notes and references}

1 Y. Zheng, Y. Jiao, L. H. Li, T. Xing, Y. Chen, M. Jaroniec and S. Z. Qiao, ACS Nano, 2014, 8, 5290-5296.

2 A. Fortunelli, W. a. Goddard III, L. Sementa and G. Barcaro, Nanoscale, 2015, 7, 4514-4521.

3 N.-T. Suen, S.-F. Hung, Q. Quan, N. Zhang, Y.-J. Xu and H. M. Chen, Chem. Soc. Rev., 2017, 46, 337-365.

4 T. Reier, M. Oezaslan and P. Strasser, ACS Catal., 2012, 2, 1765-1772.

5 S. Cherevko, S. Geiger, O. Kasian, N. Kulyk, J. P. Grote, A. Savan, B. R. Shrestha, S. Merzlikin, B. Breitbach, A. Ludwig and K. J. J. Mayrhofer, Catal. Today, 2016, 262, 170-180.

6 Y. Zhao, R. Nakamura, K. Kamiya, S. Nakanishi and K. Hashimoto, Nat. Commun., 2013, 4, 1-7.

7 Z. Zhao and Z. Xia, ACS Catal., 2016, 6, 1553-1558.

8 Z. Zhao, M. Li, L. Zhang, L. Dai and Z. Xia, Adv. Mater., 2015, 27, 6834-6840.
9 D. O'Hagan, Chem. Soc. Rev., 2008, 37, 308-319.

10 S. L. Divittorio, M. S. Dresselhaus and G. Dresselhaus, J. Mater. Res., 1993, 8, 1578-1585.

11 T. Nakajima, M. Koh, V. Gupta, B. Žemva and K. Lutar, Electrochim. Acta, 2000, 45, 1655-1661.

12 Y. S. Lee, J. Fluorine Chem., 2007, 128, 392-403.

13 I. Palchan, M. Crespin, H. Estrade-Szwarckopf and B. Rousseau, Chem. Phys. Lett., 1989, 157, 321-327.

14 G. Panomsuwan, N. Saito and T. Ishizaki, J. Mater. Chem. A, 2015, 3, 9972-9981.

15 X. Sun, Y. Zhang, P. Song, J. Pan, L. Zhuang, W. Xu and W. Xing, ACS Catal., 2013, 3, 1726-1729.

16 A. Tressaud, F. Moguet, S. Flandrois, M. Chambon, C. Guimon, G. Nanse, E. Papirer, V. Gupta and O. P. Bahl, J. Phys. Chem. Solids, 1996, 57, 745-751.

17 T. Y. Ma, J. Ran, S. Dai, M. Jaroniec and S. Z. Qiao, Angew. Chem., Int. Ed., 2015, 54, 4646-4650.

18 Z. Xiao, X. Huang, L. Xu, D. Yan, J. Huo and S. Wang, Chem. Commun., 2016, 52, 13008-13011.

19 X. Lu, W. L. Yim, B. H. R. Suryanto and C. Zhao, J. Am. Chem. Soc., 2015, 137, 2901-2907.

20 Y. Sato, K. Itoh, R. Hagiwara, T. Fukunaga and Y. Ito, Carbon, 2004, 42, 3243-3249. 